\title{
Editorial
}

\section{Otolaryngology and head-neck surgery: its areas of expertise (Subspecialties)}

Khabir Uddin Ahmed ${ }^{1}$, Nanda Kishore Sinha ${ }^{2}$

The structures of the ear, nose \& throat are closely related in their anatomy, physiology, and perhaps most significantly pathology. The strength of the clinical union of ear, nose and throat was underpinned by the acquired understanding of the organ's association within the fields of anatomy, physiology and pathology. The anatomical continuum of the inner ear, eustachian tube, nasopharynx, oropharynx and larynx explains the common spread of infections and malignancy through these cavities.

With strong historical background in ancient Egypt, Greece, China and India, the subject otolaryngology has evolved as distinct specialty as a result of lot of social and scientific evaluations, including demographic shifts, changing understanding of diseases, the development of appropriate equipment and the founding of specialist department of major universities. $^{1}$

Since the turn of the $20^{\text {th }}$ century, otolaryngology has evolved as a dignified specialty. Over the last century ENT has faced many challenges including the threat of its own demise. It incorporated new fields such as head neck surgery and new technologies such as Laser, Coblation and Radiofrequency, endoscopic surgery and cochlear implantation. Now it has become one of the most diverse and capable discipline, treating patient of all ages, from new born with congenital anomalies to an old with presbyacusis and uncoordinated balance, and a range of diversified diseases that ranges from malignancy to hearing loss.
In our settings, some 25-30 years ago, the ENT departments in all the medical colleges were a small, dark and mysterious place. General surgery enjoyed dominance in the undergraduate curriculum and in the operation theatres. But, by this time things has changed a lot. ORL-HNS has become an exciting and progressive area of medical science with lot of diversification in disease explanation and management, incorporating a lot of newer technologies and taking a pivotal role in the management of devastating head neck malignancies with a rational and humanitarian approach. All these achievements were possible due to our predecessor's strong professional leadership and robust training both in home and abroad.

Inevitably, there is a point of saturation at which one individual can do no more. The ever increasing body of knowledge within ENT has begun to subdivide. Otology, Rhinology, Laryngology and head-neck surgery are advancing separately, and the creation of their own journals and societies is indicative of this. ${ }^{2,3}$

American academy of ORL - HNS describes seven areas of expertise in the field of Otolaryngology. ${ }^{4}$

- Allergy - Treatment by medication, immunotherapy.

- Facial plastic and reconstructive surgery - Cosmetic, functional and reconstructive surgical treatment.

- Head and Neck - Cancerous and noncancerous tumors in the head \& neck including thyroid and parathyroid. 
- Laryngology - Disorder of the throat including voice and swallowing problems.

- Otology-Diseases of the ear including trauma, infection, tumor and nerve pathway disorders.

- Paediatric ORL - Diseases in children with special ENT problems including birth defects of the head and neck and developmental delay.

- Rhinology - Disorders of nose and sinuses, sleep disorders.

Otology itself is going through a period of super-specialization whereby sophisticated developments have become conductive to its fragmentation into neurotology, skull base surgery, middle ear surgery and implantation surgery. ${ }^{5}$ Endoscopic ear surgery and robotic mastoid surgery are recent advancements in otology.

To the benefit of the patient, there has been a shift towards minimally invasive surgical procedures', such as use of endoscopes in nasal sinuses, ear, salivary glands (sialoendoscopy), thyroid surgery etc, and this requires a different subset of skills, in addition to those needed for open surgery. Recently there are even discussions about the possible application of remote access robotic surgery. ${ }^{6,7}$

Robots are broadly defined as mechatronic creations that can perform automated or guided tasks. Surgical assist robots are those that modify a surgeons movement either locally or via remote control ( for example teleoperation) $)^{8}$

As these innovations arise such as microscope, laser, endoscopes, robots, the things become more complex, It becomes hard for a person to master them all due to unavoidable personal, social, economical and establishmental reasons.

An important argument for specialization is that it is in the patient's interest to do so. It is a widely recognized principle of economics that specialization can improve efficiency and outcome. ${ }^{9}$ This has already been observed in medical practice. Treatment outcomes are superior in patients who have received cares from specialist trained and experienced in the relevant area. In this relation, another issue also arises. Usually a superspecialist doctor is a part of a multidisciplinary team (MDT) to deliver allied health care. ${ }^{10}$ As in cochlear implantation, the surgeon's work is a defined role rather than autonomous, as the role of a radiologist, audiologist, speech and language therapist cannot be ruled out in this situation. Multidisciplinary teams are also likely, to propagate the training of "disease" oriented specialist, rather than procedure oriented ones. ${ }^{10,11}$ For example the competence of a surgeon may based on their ability to manage otosclerosis rather than on simply being able to perform a stapedectomy. ${ }^{11}$

As the trends of specialization continues the need for an ENT generalist has become under scrutiny. A large proportion of ENT works is based on more general, routine procedures and these mirrors the population's disease profile. ${ }^{11,12}$ Most of the ENT disease are diverse and complex. Otolaryngologists often manage both surgical and nonsurgical cases as there were traditionally no conjoined medical specialties. ENT generalists are capable of fully managing patients with common uncomplicated complaints. An ENT generalist is also capable of compatibly handling all ENT emergencies. A superspecialist with limited general training would not be equipped to deal with acute presentations; they may not even recognize them.

The work of the medical profession is under intense public's scrutiny, and this has rightly lead greater awareness of patient oriented care.

Experience is crucial in attaining the necessary ability to asses and manage emergency situations. Substandard emergency cover 
could pose a major danger with ENT emergencies having potentially catastrophic outcomes such as - permanent hearing loss, apnoea, brain damage and death.

In our perspective majority of ENT generalist should provide most of the ENT care at district's, with a sufficient number of super specialists should available at tertiary level teaching hospitals.

It may be concluded here that, in the interest of patient's safety and individual surgeon's carrier initiative, all ENT trainees should receive some form of basic surgical training, in addition to becoming competent in the management of common ENT diseases and emergencies.

Beyond this, training for a limited number should be centered on a particular specialty or perhaps even more advanced emergency training.

Although specialization is undoubtedly the direction of the future, the achievements of our predecessors should not be forgotten. Our professional leadership should have a foresight for a comprehensive solution about the newer subspecialties, remembering and honouring the past, when shaping the future of the specialty .

\section{Prof. Khabir Uddin Ahmed ${ }^{1}$, Dr. Nanda Kishore Sinha²}

${ }^{1}$ Prof \& Head, Dept. of Otolaryngology \& Head- Neck Surgery, Shaheed Suhrawardy Medical college, Dhaka, ${ }^{2}$ Associate Prof. Dept. of Otolaryngology \& Head- Neck surgery Shaheed Suhrawardy Medical college, Dhaka. mail id > khabir1960@yahoo.com

\section{References:}

1. S.Yalamanchili, why should disorders of the Ear, Nose and throat be treated by the same speciality ? can this situation persists ? The journal of laryngology \& otology(2009);123: 367-371.

2. Ferlito A, Buckley JG, Ossoff RH, Rinaldo A, Weir N, The future of layngology. Acta otolaryngol 2001; 121 : 859- 67.

3. Margan M, Gupta D. A Carrer in Otorhinolarymgo logy. BMJ careers 2002; 324 :S89.

4. Internet. Health information of American Academy of otolaryngology Head and Neck surgery available at www.entnet. org/ Healthinformation/otolaryngologist.cfm

5. Irving RM, Proops DW, The future of $\mathrm{ORL}-\mathrm{HNS}$ and associated specialities series : The future of otology . J Laryngol Otol 2000; $114: 3-5$.

6. Darzi A, Mckay S. Recent advances in minimal access surgery. BMJ 2002; 324: 31 -34.

7. Gourin CG, Terris DJ. Surgical robotics in otolaryngology - expanding the tecnology envelope. Curr opin otolaryngol Head Neck surg 2004; 12 : 204-208.

8. Taylor RH. A Perspective on medical robotics Proc IEEE 2006; 94(9): 1652 64.

9. Smith A. An inquiry into the nature and causes of the wealth of nations, London : Printed for strahan W. and Cadall T., 1776.

10. Ribeiro B. Surgery in the $21^{\text {st }}$ century. Joint committee on higher surgical training [ www.jchst.org] london : The Royal college of surgens of England; c2006.

11. Browning GG, Burton MJ, The future of ORL- HNS and associated specialties series: Quality issues in otorhinolaryngology: part -1, Laryngol otol 2000; $114: 817-20$

12. Van den Brock P. Global training in ORLHNS training in otorhinolaryngology : A European perspective. J Laryngol Otol 2000; 114 : 331- 5. 